\title{
DIFFERENTIATION OF RAT OSTEOBLAST-LIKE CELLS IN MONOLAYER AND MICROMASS CULTURES
}

\author{
I. Gerber ${ }^{1,2}$ and I. ap Gwynn ${ }^{3}$
}

\author{
${ }^{1}$ Institute of Cell Biology, ETH Hoenggerberg, CH-8093 Zürich, Switzerland \\ ${ }^{2}$ AO Research Institute, Clavadelerstrasse, CH-7270 Davos Platz, Switzerland \\ ${ }^{3}$ Institute of Biological Sciences, The University of Wales, Aberystwyth, Ceredigion SY23 3DA, Wales, U.K..
}

\begin{abstract}
During intramembranous bone formation, preosteoblasts condense, differentiate into osteoblasts and deposit bone matrix. We compared the differentiation process of rat calvarial osteoblast-like cells inoculated as micromasses, which mimic the in vivo condensation process, with cells inoculated as monolayers. The cells were analysed morphologically at 1,2 and 3 weeks by light microscopy (alkaline phosphatase activity, mineralization), by transmission electron microscopy, and biochemically (collagen typing, alkaline phosphatase activity, protein and DNA content). The cells inoculated as monolayers formed alkaline phosphatase positive and mineralized nodules during the culture period. The cells inoculated as a micromass formed a large mineralized area consisting of smaller nodules. The ultrastructure of the cells in both culture systems showed the typical features of osteoblasts and osteocytes. The main difference between monolayer and micromass cultures was found after 1 week in culture. The cells inoculated as a micromass formed a multilayer of cells. The cytoplasm contained rER, mitochondria, vesicles and ribosomes. There were abundant collagen fibrils in membrane folds and in the extracellular matrix. This was in contrast to the cells in monolayer culture which showed hardly any collagen fibrils in the extracellular matrix. The promotion of the differentiation was also confirmed by biochemical data showing that the DNA content was lower in the micromass than in the monolayer cultures during the culture period. These results show that micromass, as compared to monolayer, culture promotes the differentiation of rat osteoblast-like cells in vitro.
\end{abstract}

Key Words: Osteoblasts; cell culture; micromass culture; monolayer culture; differentiation; inoculation; light microscopy; ultrastructure; biochemistry

Address for correspondence

Isabel Gerber

Institute of Cell Biology

ETH Hoenggerberg

CH-8093 Zürich

Switzerland

Tel.: ++41-1-6333360

Fax: ++41-1-6331069

E-mail: isabelle.gerber@cell.biol.ethz.ch

\section{Introduction}

The in vitro osteoblast developmental sequence can be considered as a re-initiation of events occurring in vivo, because the freshly isolated cells have similar levels of bone phenotype-associated transcripts (Owen et al., 1990). There are three principal periods in the differentiation of rat osteoblasts in culture: proliferation, extracellular matrix maturation and mineralization (Owen et al., 1990). Mineralization of the formed nodules occurs after 2-3 weeks in monolayer cultures (Bellows et al., 1991; Collin et al., 1992; Gerstenfeld et al., 1987). In contrast, the mineralization in micromass cultures starts at 1 week and by 2-3 weeks most of the culture consists of mineralized tissue (Masquelier et al., 1990; Zimmermann et al., 1988). In this study we compared the differentiation process of rat osteoblasts in vitro, inoculated with the same cell number per dish, either as monolayer cultures or as micromass cultures. To follow the differentiation process, the cells were analyzed at 1, 2, and 3 weeks by observing the ultrastructure of the cells, by histochemical detection of the alkaline phosphatase activity (ALP) and von Kossa stain for mineralization. Furthermore, ALP activity, DNA and protein content were quantified at 1,2 and 3 weeks.

\section{Materials and Methods}

\section{Materials}

All tissue culture disposable materials were purchased from Falcon (Becton Dickinson AG, Basel, Switzerland). All growth media and fetal calf serum were purchased from Gibco (Invitrogen, Basel, Switzerland). All chemicals were purchased from Fluka (Buchs, Switzerland) when not otherwise stated.

\section{Methods}

Osteoblast cell culture. Parietal and frontal calvariae (4 per animal) were aseptically explanted from 6 day old IcoIbm rats. The calvariae were placed in Tyrode's buffered salt solution calcium- and magnesium-free (TBSS). The periosteum and endosteum were removed enzymatically with $0.05 \%$ trypsin (1:250; Sigma, Buchs, Switzerland) and $0.02 \%$ collagenase A $(0.76 \mathrm{U} / \mathrm{mg}$; Roche Diagnostics, Rotkreuz, Switzerland) dissolved in TBSS (40 calvaria/20 ml). The calvariae were shaken for $70 \mathrm{~min}$ in a water bath at $37^{\circ} \mathrm{C}$. After washing with TBSS, they were treated with $0.02 \%$ collagenase $\mathrm{A}$ in $\mathrm{BGJ}_{\mathrm{b}}$ FittonJackson modification for $3 \mathrm{~h}$ Afterwards the calvariae were 
washed with BGJ $_{\mathrm{b}}$ supplemented with $10 \%$ foetal calf serum. The calvariae were then transferred into $60 \mathrm{~mm}$ culture dishes ( 4 frontal and 4 parietal/dish). The growth medium supplemented with $10 \%$ FCS and $50 \mu \mathrm{g} / \mathrm{ml}$ ascorbate was changed completely every $48 \mathrm{~h}$. The culture was kept for 3 weeks. After 3 weeks the migrated cells and the calvariae were washed with TBSS and $5 \mathrm{ml}$ of TBSS containing $0.05 \%$ trypsin and $0.02 \%$ collagenase A $(0.76 \mathrm{U} /$ $\mathrm{mg}$ ) was added. After $1 \mathrm{~h}$ in the incubator the dish was washed several times with culture medium BGJ $_{\mathrm{b}}$ supplemented with $10 \%$ FCS. The cells obtained were filtered through a $40 \mu \mathrm{m}$ nylon mesh. The suspended cells were centrifuged at $600 \mathrm{~g}$ for $5 \mathrm{~min}$. The cell pellet was resuspended in serum containing medium $B_{\mathrm{b}} \mathrm{b}$ and centrifuged. The viability of the resuspended cells was tested by the 'dye exclusion' of $0.4 \%$ trypan blue and the cells counted in a haemocytometer. The inoculation densities were $2 \cdot 10^{5} / 10 \mathrm{~cm}^{2}$ for monolayers and $2 \cdot 10^{5} / 30 \mu \mathrm{l} / 10 \mathrm{~cm}^{2}$ for micromasses. The micromass cultures were kept for $1 \mathrm{~h}$ in the incubator before $2 \mathrm{ml}$ growth medium was added. All the cultures were kept at $37^{\circ} \mathrm{C}$ in a humidified atmosphere of $5 \% \mathrm{CO}_{2}$ and $95 \%$ air. The media were completely changed every $48 \mathrm{~h}$. The growth medium was supplemented with $50 \mu \mathrm{g} / \mathrm{ml}$ ascorbate.

Light microscopy. After 1,2 and 3 weeks the cultures were stained histochemically for the alkaline phosphatase, using the Sigma Kit no. 85L (Sigma, Buchs, Switzerland). As a result, an insoluble, visible blue pigment is formed at sites of phosphatase activity. At 2 and 3 weeks mineralization was detected by von Kossa staining.

Transmission electron microscopy (TEM). At 1, 2 and 3 weeks, the cell cultures were fixed with $2.5 \%$ glutataraldehyde in $0.1 \mathrm{M}$ cacodylate buffer $\mathrm{pH} 7.4$ for 20 min, postfixation in $1 \% \mathrm{OsO}_{4}$ in $0.1 \mathrm{M}$ cacodylate buffer $\mathrm{pH} 7.4$ for $1 \mathrm{~h}$ at $4{ }^{\circ} \mathrm{C}$, then $2 \%$ aqueous uranyl acetate for $1 \mathrm{~h}$ at room temperature; dehydration in an ethanol series and embedding in LR White (London Resin Co, Basingstoke, U.K.). Ultrathin sections through the nodular area of monolayer cultures were cut with a Drukker Diamond knife (Drukker International, Cuijk, The Netherlands) on a LKB III Microtome (LKB, Bromma, Sweden) and stained with $2 \%$ uranyl acetate and lead citrate (Reynolds, 1963). Osmium rich regions, i.e., the nodules in the monolayer, and the centers of the micromass cultures, were selected respectively. The sections were examined using a JEOL (Tokyo, Japan) JEM 100CX transmission electron microscope operated at $100 \mathrm{kV}$.

Biochemistry. Whole cultures were washed with phosphate buffered saline and $500 \mu 10.25 \mathrm{M}$ sucrose $/ 35 \mathrm{~mm}$ dish was added. The cells were scrubbed off the dish and transferred into a cryotube and frozen at $-80^{\circ} \mathrm{C}$. Immediately before the assays, the cells were thawed and sonicated $(3 \times 20 \mathrm{~s})$ at $70 \mathrm{~W}$ and $20 \mathrm{kHz}$ on ice. The samples were a_nalysed in a Perkin Elmer UV/VIS Spectrophotometer Lambda 12 (PerkinElmer Instruments,
Huenenberg, Switzerland) and in a Hoefer TKO 100 MiniFluorometer (Hoefer Scientific Instruments, San Francisco, CA) for DNA determination.

Alkaline phosphatase activity (ALP). A Sigma Kit no. 245 (Sigma, Buchs, Switzerland) was used for the quantitative, kinetic determination of alkaline phosphatase activity.

Total protein. The Bio-Rad protein assay kit II (BioRad, Glattbrugg, Switzerland) was used with bovine serum albumin as standards.

DNA. A simple and rapid assay for quantitative DNA determination in crude homogenates was used (Labarca and Paigen, 1980). Each sample was diluted with $3 \mathrm{ml}$ of phosphate buffered saline, $\mathrm{pH} 7.4$ containing $2 \mathrm{M} \mathrm{NaCl}$ (DPBS) and sonicated as described above. Then aliquots were mixed with $0.1 \mu \mathrm{g} / \mathrm{ml}$ Hoechst 33258 in DPBS and the fluorescence was read in a Hoefer TKO 100 MiniFluorometer.

Collagen. During the culture period, the growth medium was supplemented with $60 \mathrm{mg} / \mathrm{ml} \mathrm{b}$-aminopropionitrile to prevent cross linking of the collagen fibrils. Whole cell layers were harvested and processed, as previously described for chondrocyte cultures (Bruckner et al., 1989). After 3 weeks in culture whole culture dishes were frozen (calvaria and the outgrown cell were separated), thawed, homogenized and treated with $25 \mathrm{ml}$ of $0.5 \mathrm{M}$ acetic acid, containing $0.2 \mathrm{M} \mathrm{NaCl}$ and $1 \mathrm{mg} / \mathrm{ml}$ of pep$\sin$ and stirred for $48 \mathrm{~h}$ at $4^{\circ} \mathrm{C}$. To inactivate pepsin $1 / 10$ vol of $1 \mathrm{M}$ unbuffered Tris was added and the samples were neutralized by addition of $10 \mathrm{M} \mathrm{NaOH}$, adjusted to $1 \mathrm{M}$ in $\mathrm{Na}^{+}$-ion concentration by addition of solid $\mathrm{NaCl}$, and extracted for $48 \mathrm{~h}$ at $4^{\circ} \mathrm{C}$. The undigested residue was centrifuged at $27^{\prime} 000 \mathrm{~g}$. The collagens were precipi-

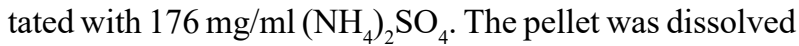
in $0.4 \mathrm{M} \mathrm{NaCl}, 0.1 \mathrm{M}$ Tris-HCl, $\mathrm{pH}$ 7.4. Aliquots were precipitated with $3 \mathrm{vol}$ ethanol, and dissolved in $0.1 \mathrm{M}$ Tris $\mathrm{HCl}, 0.8 \mathrm{M}$ urea, $2 \% \mathrm{SDS}, 10 \%$ glycerine, $\mathrm{pH}$ 6.8. A first aliquot remained unreduced, a second aliquot was reduced with $2 \%$ b-mercapto-ethanol. Sodium dodecyl sulfate-polyacrylamide gel elctrophoresis (SDS-PAGE) was performed as described by (Laemmli, 1970), using a $4.5 \%$ stacking gel and a $4.5 \%$ - $15 \%$ gradient running gel. Collagen standards were run in parallel with the samples. The electrophoresis was performed at $220 \mathrm{~V}$, followed by staining with Coomassie blue.

Statistics. To compare the treatment, contrast analysis of variance models was performed. Main effects and interaction effects were examined by F-Tests. 'Least Squares Means' were calculated to yield average means accounting for the other variables in the model. LS Means were compared by using Tukey's multiple range test. QQ-Plots of the residuals and Tukey-Anscombe plots (residuals $\mathrm{x}$ predicted) were analyzed to check for a normal distribution assumption. 

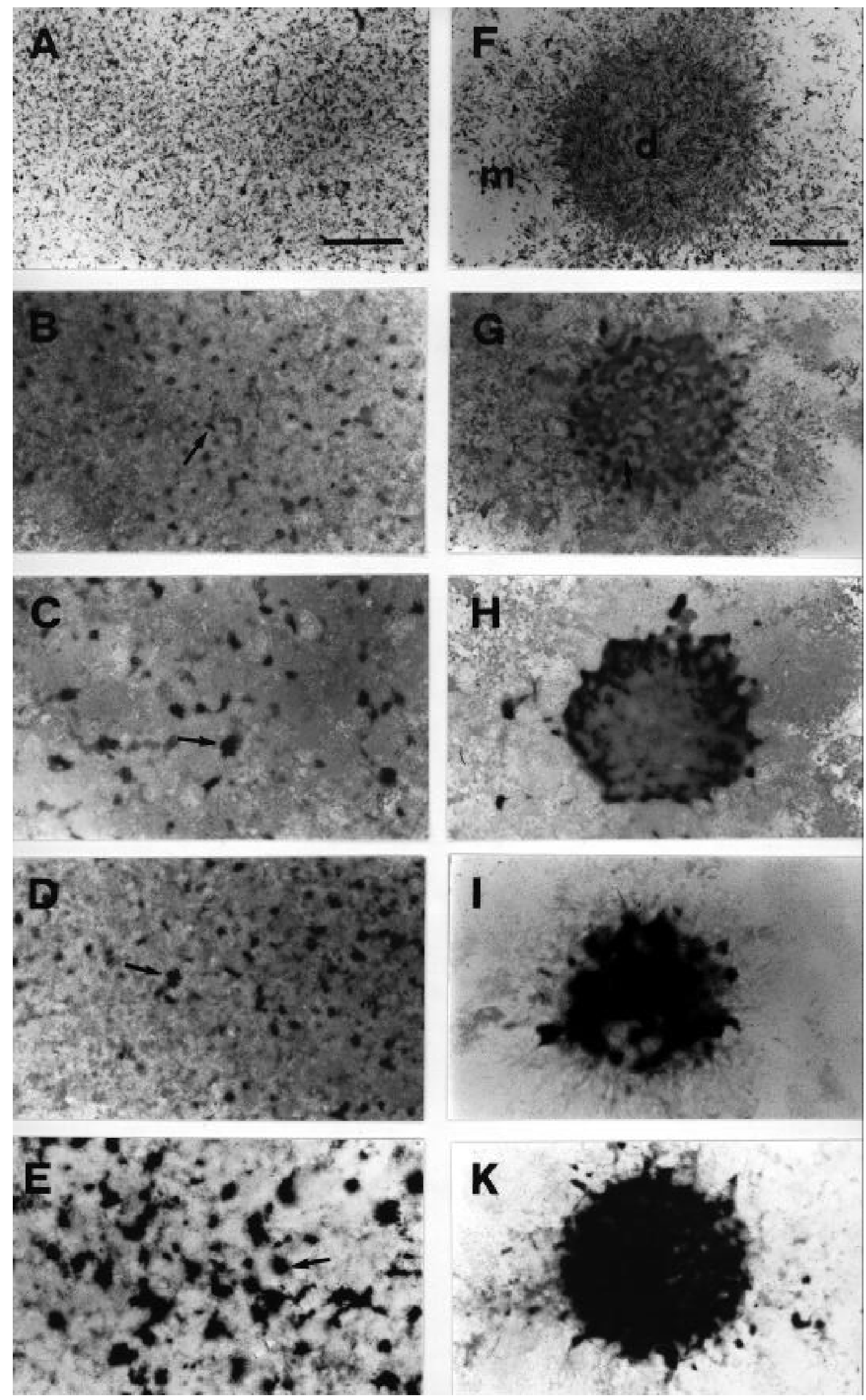

Figure 1. Light microscopical view of monolayer (A-E) and micromass (F-K) cultures at 1,2 and 3 weeks. Same magnification in all pictures, bar scale $3 \mathrm{~mm}$. Nodule formation (arrow), originally inoculated drop of cells (d) and migrated cells (m). A) ALP activity at 1 week. B) ALP activity at 2 weeks. C) ALP activity at 3 weeks. D) mineralization at 2 weeks. E) mineralization at 3 weeks. F) ALP activity at 1 week. G) ALP activity at 2 weeks. H) ALP activity at 3 weeks. I) mineralization at 2 weeks. K) mineralization at 3 weeks. 

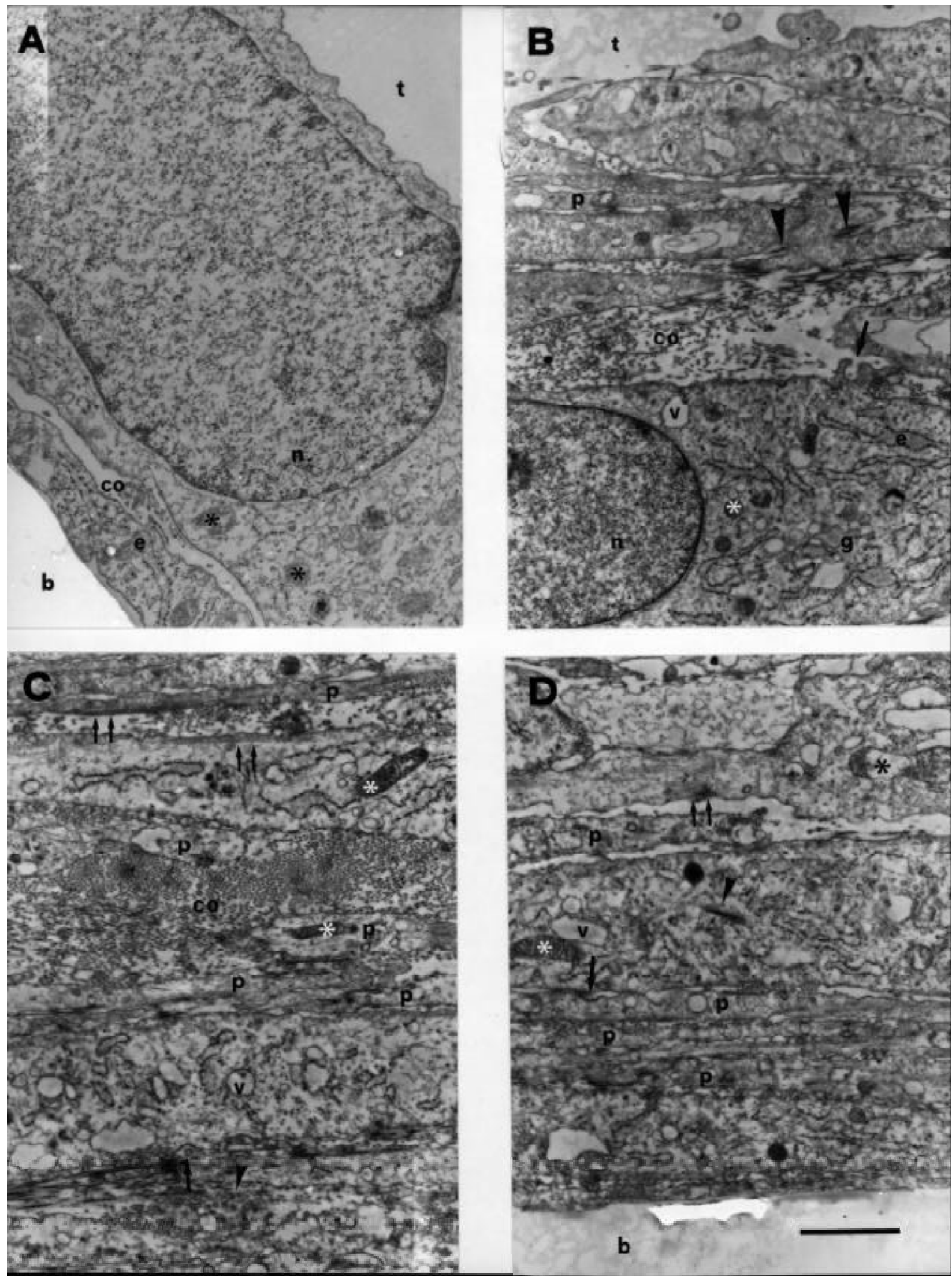

Figure 2. Ultrastructure at 1 week. Same magnification in all pictures, bar scale $2 \mathrm{~mm}$. Growth medium interface (t), cultures dish surface (b), nucleus (n), endoplasmatic reticulum (e), mitochondria (asterisk), vesicle (v), Golgi area (g), cytoskeletal elements (double arrow), cell processes (p), endo/exocytosis (arrow), collagen fibrils (co), 'extruding' collagen fibrils (large arrow head), details shown in next figure (small arrow head). A) Monolayer. B) Micromass; top cell layers. C) Micromass; middle cell layers. D) Micromass ; lower cell layers. 

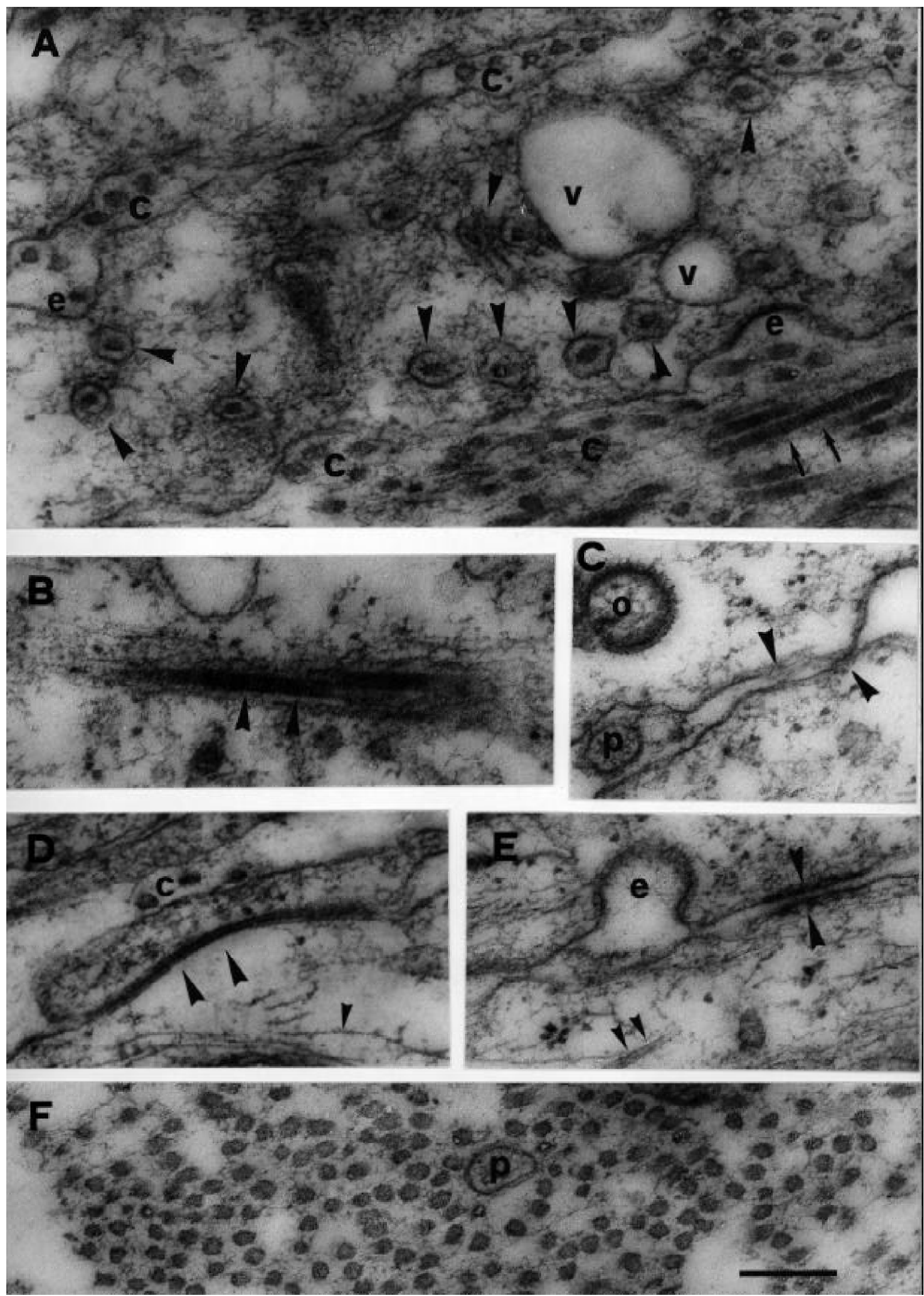

Figure 3. Detail of ultrastructure of micromass cultures at 1 week. Same magnification in all pictures; bar scale $150 \mathrm{~nm}$. Collagen fibrils in cross section (c), endo/exocytosis (e), cell process (p). (A) cross section of collagen fibrils in membrane folds (arrow head), cross striation of collagen fibrils (arrow), veslicle (v). B) longitudinal section of collagen fibrils (double arrow head) in membrane fold C). Focal contact points (arrow head), annular gap junction (o). D) gap junction (large arrow head), cytoskeletal element (small arrow head). E) cell membrane in close apposition (large arrow head), thick cytoskeletal element (small arrow head). F) Extracellular collagen fibrils in cross section. 


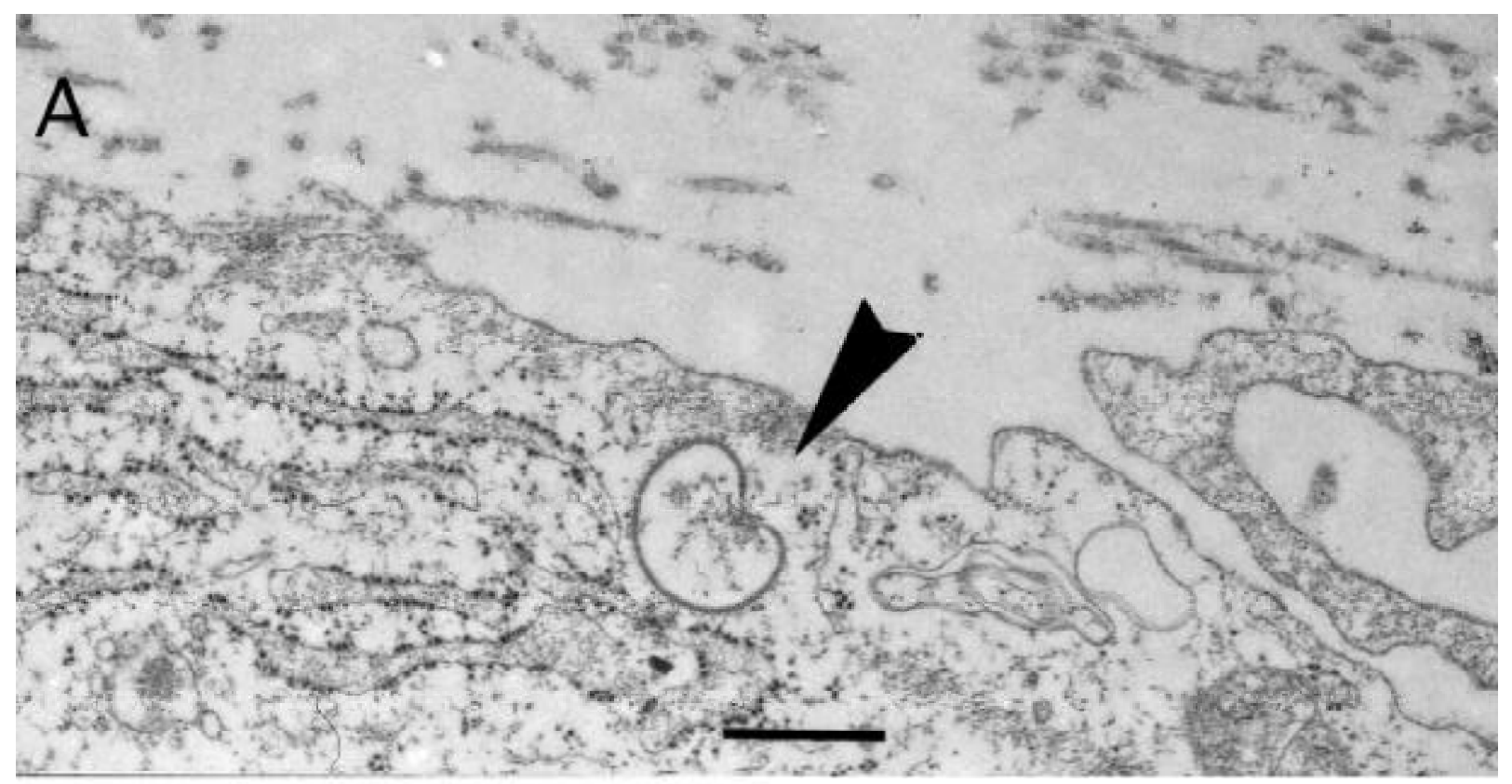

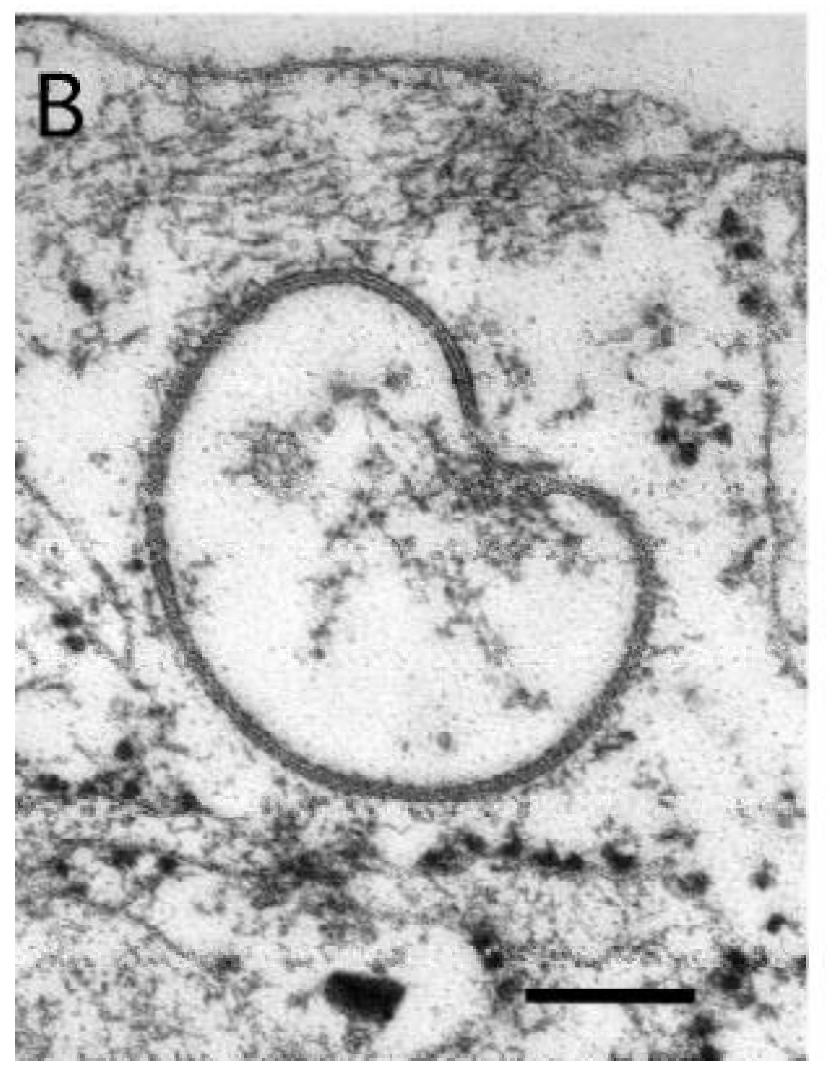

Results

ALP and mineralization. Most of the cells cultured as monolayers stained positively for ALP after 1 week (Fig. 1A). After 2 weeks there were ALP positive and calcified nodules, which increased in size and number at 3 weeks (Fig. 1B-1E). In micromass cultures at 1 week, the original drop consisted of ALP positive cells and there were many ALP positive cells migrating off the original drop (Fig. 1F). At 2 weeks, the original drop of inoculated cells consisted of smaller ALP positive and mineralized nod-
Figure 4. A) Ultrastucture at 1 week of oval gap junction (arrow head), bar scale $500 \mathrm{~nm}$. B) Detail of A; bar scale $75 \mathrm{~nm}$.

ules (Fig. 1G, 1I). At 3 weeks, the original drop of cells was fully mineralized and the ALP positive cells were confluent (Fig. 1H, 1K).

TEM Ultrastructure. Monolayer cultures at 1 week were different from the micromass ones. The monolayer culture had only some areas with more than 2 cell layers (Fig. 2A). There was hardly any collagen between the cell layers of the monolayer. The cytoplasm contained rER, which contained material with medium density, mitochondria, and many vesicles and ribosomes (Fig. 2A). The presence of cytoskeletal elements was not evident with the fixation procedure we used.

The micromass at 1 week consisted of a thick multilayer of elongated cells (Fig. 2B-2D). Between the cells in the middle layers there were abundant orthogonally oriented collagen fibrils and typical cross-striation was seen (Fig. 2B, 2C). These fibrils were also found in membrane folds but the frequency varied from section to section (Fig. 3A, 3B). The collagen fibrils in membrane folds resembled the extracellular fibrils in diameter, staining pattern, and electron density (Fig. 3A, 3F). The diameter of the collagen fibrils was rather uniform at approximately $50 \mathrm{~nm}$. The lower cell layers only had a few collagen fibrils in the adjoining extracellular matrix (Fig. 2D). The cells had many cell-cell contacts either as focal points or with longer cell membrane areas in very close apposition (Fig. 3C-3E). There were gap junctions observed with various appearances such as annular (Fig. 3C), stretched (Fig. 3D) or oval (Fig. 4). The cytoplasm contained abundant rER, which was dilated in some cells, and many free ribosomes (Fig. 2B-2D). The mitochondria were numerous and of various sizes and shapes, accounting for sec- 


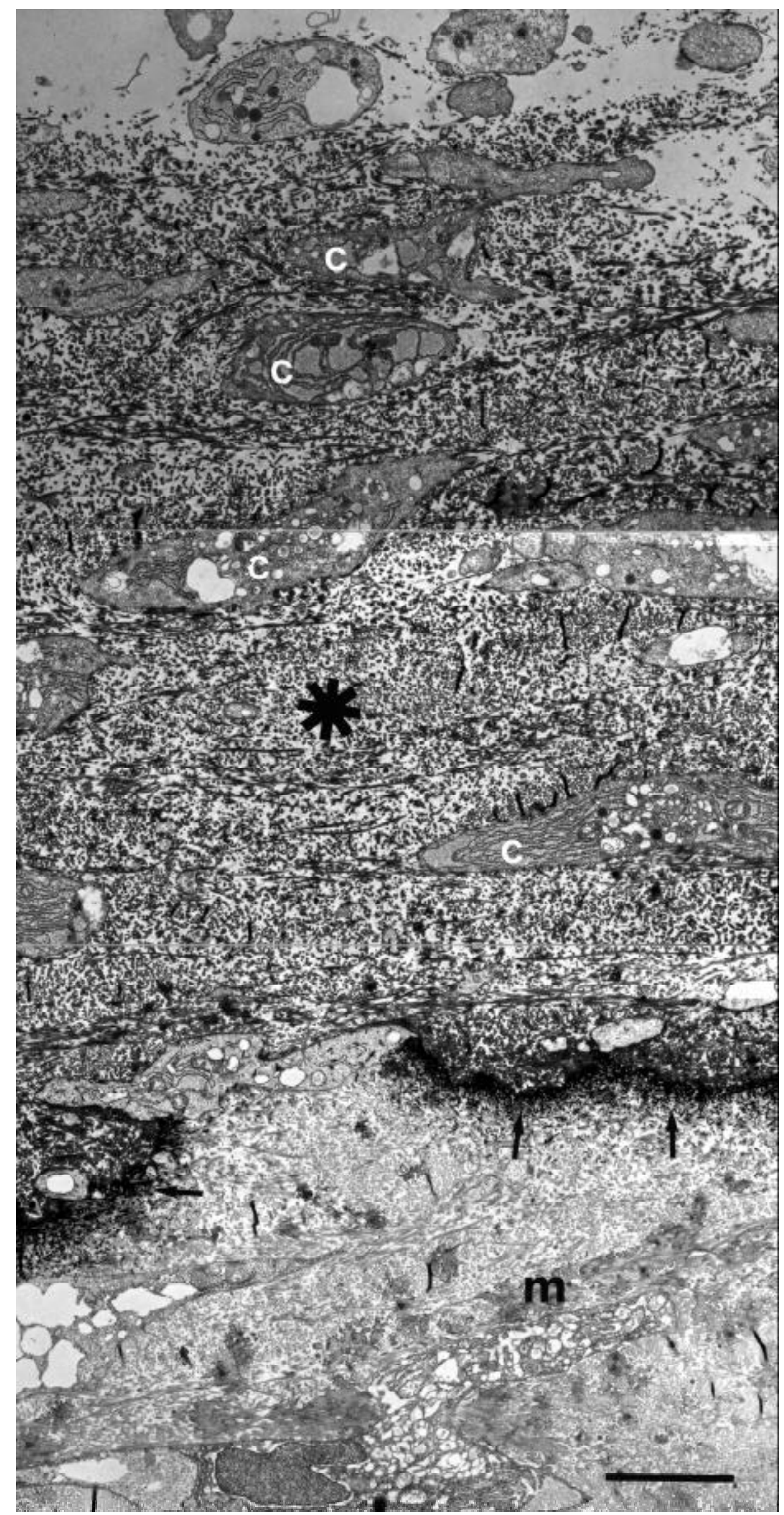

Figure 5. Ultrastructure at 3 weeks. Bar scale $5 \mathrm{~mm}$. Cells (c) separated by collagen fibrils (star), mineralized matrix (m), mineralization front (arrow). 


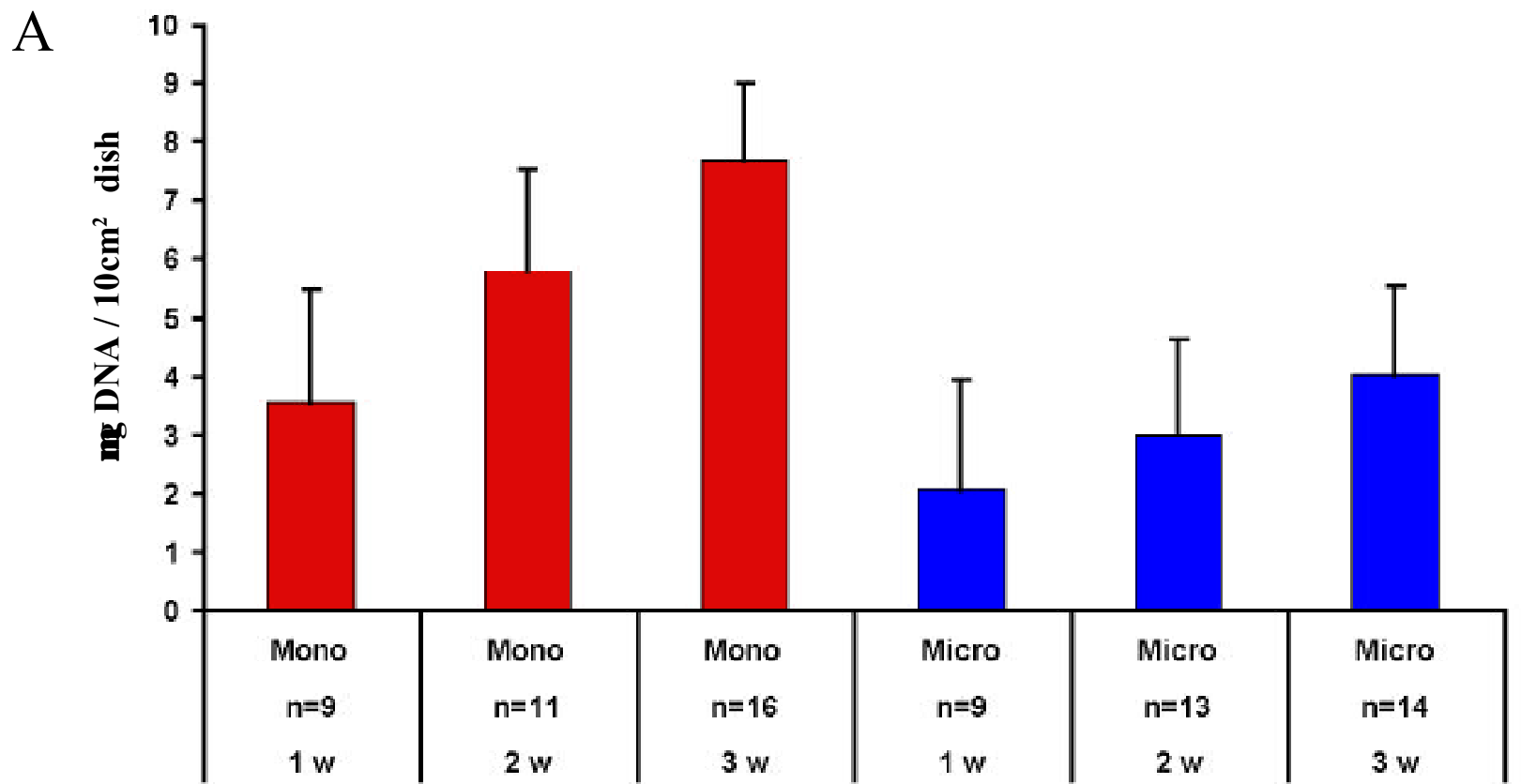

B

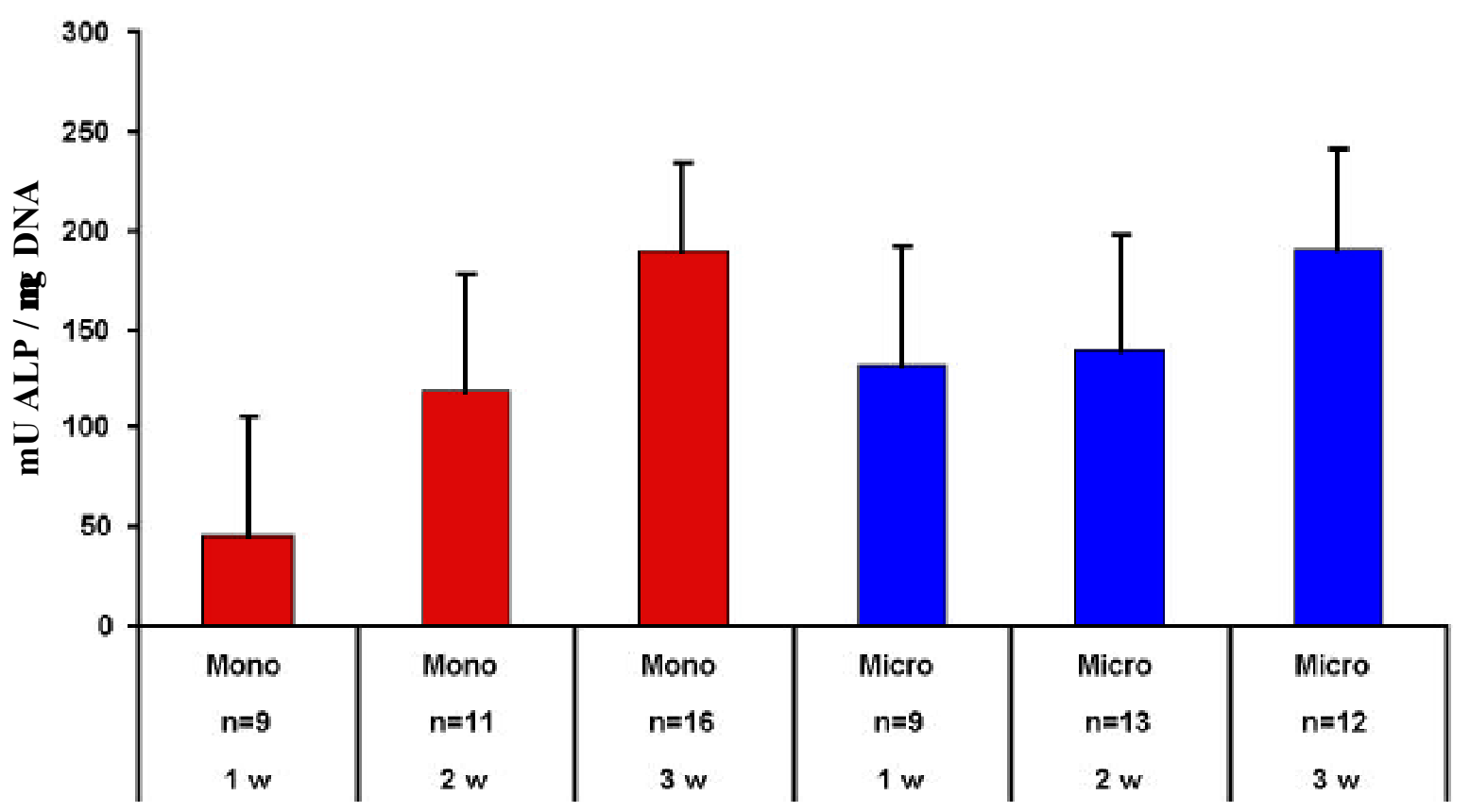

C

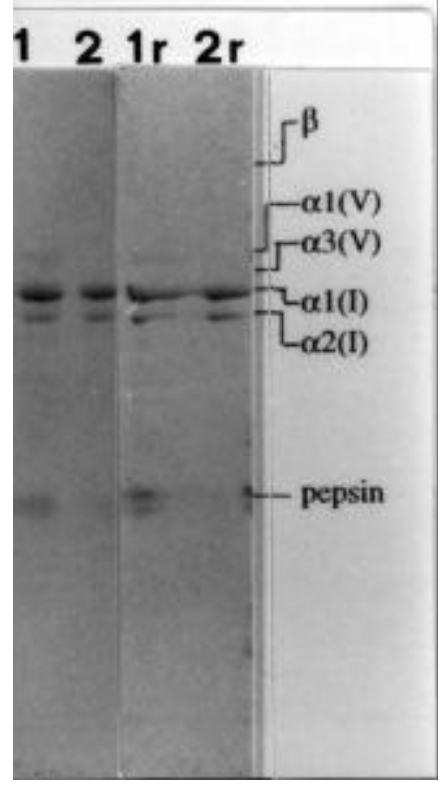

Figure 6. Biochemical analysis of monolayer (Mono) and micromass (Micro) cultures at 1, 2 and 3 weeks $(1 \mathrm{w}, 2 \mathrm{w}, 3 \mathrm{w}) . \mathrm{n}=$ independent experiments. Least squares means \pm 1.98 standard error. A) Total DNA content $/ 10 \mathrm{~cm}^{2}$ dish. B). ALP activity per DNA. C). SDS-PAGE (4.5-15\%) of collagens extracted by pepsin digestion from whole cultures at 3 weeks stained with Coomassie blue; r: Samples reduced with 2\% 2mercapto ethanol; lanes 1, 1r: monolayer; lanes 2, 2r: micromass. 
tioning effects, ranging from round to banana-shaped (Fig. 2B-2D). The Golgi area and the vesicles were numerous, showing diverse ranges of size, form and electron density (Fig. 2B-2D). There were coated pino/exocytotic vesicles fused with the plasma membrane (Fig. 2B-2D, Fig. 3A, E). Cytoskeletal filaments of varying diameters were present (Fig. 2B-2D; Fig. 3D, E). Many microfilaments were running parallel to the plasma membrane in the cortical region of the cells. Some filaments of larger diameter were also present (Fig. 3E). Many cell processes had prominent densely packed microfilaments lying mainly parallel to the culture dish surface (Fig. 2B-2D).

At 2 and 3 weeks, the ultrastructure of the nodules of the monolayer and the centre of the micromass were similar (Fig. 5). The cells in monolayer and micromass culture were characterized as described for micromass at 1 week. The cells deeper in the multilayer were completely surrounded by a mineralized matrix (Fig. 5). The amount of collagenous matrix further increased as did the mineralized zones which coalesced into a seam. The cells were separated by massive collagen layers (Fig. 5). The bulk of the orthogonally arranged collagen fibrils was found in the middle to upper cell layers. The diameter of collagen fibrils was larger than at 1 week and varied from 50 to more than $100 \mathrm{~nm}$. The collagen fibrils were also found in membrane folds (not shown).

Biochemistry. The observed increase in the cell density was confirmed by the quantification of the DNA content. The monolayer culture had a significantly $(\mathrm{p}<0.015)$ higher DNA content at 3 weeks than at 1 week (Fig. 6A). The increase in the DNA content in micromass culture was non significant over time. Furthermore, the micromass cultures had a significantly $(\mathrm{p}<0.015)$ lower DNA content than monolayers at 3 weeks (Fig. 6A). This indicated that the cells inoculated as monolayers have a higher proliferation rate than the cells kept as micromass cultures. The total protein content and the total protein content expressed per mg DNA of the monolayer or the micromass cultures did not increase significantly during the culture time (data not shown). The progression of differentiation was also seen on the biochemical level, in such a way that the ALP activity expressed per mg DNA of the monolayer was significantly $(p<0.008)$ higher at 3 weeks than at 1 week while no significant differences in the ALP activity per DNA were observed in the micromass during culture time (Fig. 6B). The micromass cultures had a higher ALP activity per DNA than the monolayer cultures but the differences were non significant. These results provided evidence that the cells in micromass cultures attained a highly differentiated state relatively early. The isolated cells inoculated either as monolayer or micromass produced mainly collagen type I, some collagen type V (Fig. 6C).

\section{Discussion}

The results of this study showed that cell-cell contacts, induced by micromass cultures, promoted the formation of differentiated osteoblasts at 1 week. These findings were based on ultrastructural observations and biochemical analysis.

The cells in micromass cultures formed a multilayer consisting of elongated cells separated by abundant orthogonally oriented collagen fibrils with a rather uniform diameter and the typical cross-striation. The ultrastructure of the cells kept as micromasses showed the typical features of osteoblasts described by others (Hancox and Boothroyd, 1965; Weinger and Holtrop, 1974).

Osteoblasts, cultured in monolayers rather than micromasses, were different. Hardly any collagen was detectable between the cell layers. The cytoplasm also tended to contain less organelles at 1 week, but after 2 weeks there were no detectable ultrastructural differences. Gerstenfeld (Gerstenfeld et al., 1993), describes osteoblasts as being flattened with small nuclei and some cytoplasmic organelles, such as ribosomes, ER, and a few mitochondria and vesicles at early culture times. During the culture time, the progressive increase in size and organelle content correspond to the greater metabolic activity of these cells during their post-proliferative period of active extracellular matrix synthesis (Gerstenfeld et al., 1993).

Furthermore, collagen fibrils were often found within membrane folds. These findings were identical to those described in tendon fibroblasts (Trelstad and Hayashi, 1979). The close contact between some cells by tight junctions, gap junctions or by apposition of their plasma membranes has also been described previously (Arana-Chavez et al., 1995). We also found oval and annular gap junctions (Shapiro, 1997) predominantly in micromass cultures. There is much evidence that the formation of cellcell contacts is fundamental for the differentiation of osteoblasts. Cells of the osteogenic lineage form a continuous protoplasmic network that extends from the osteocytes to the vascular endothelium, passing through osteoblasts (or bone lining cells) and stromal cells (Palazzini et al., 1998). Gap junctions occur at these sides, enabling metabolic and electric coupling and thus forming a functional syncytium (Palazzini et al., 1998). Gapjunctional communication (GJC) is required for the maturation process of osteblastic cells MC3T3-E1 in culture (Schiller et al., 2001a). As the cell progress toward a mature phenotype, mRNA and protein for connexin 43 (Cx43) and gap-junctional intercellular communication (GJC) are increased (Schiller et al., 2001b). Such an increased GJC was accompanied by a parallel decrease in ALP activity and by an increase of osteocalcin expression (Romanello et al., 2001). The effect of GJC on proliferation is controversial. On one hand an enhancement of Cx43 expression increases proliferation and differentiation of an osteoblast-like cell line UMR 106-01 (Gramsch et al., 2001). On the other hand, temperature sensitive osteoblastic cell line exhibits an inhibition of proliferation, increasing Cx43 mRNA and protein expression and increased GJC at the permissive temperature (Donahue et al., 2000). Altering gap junctional permeability by manipulating the expression of $\mathrm{Cx} 43$ and $\mathrm{Cx} 45$ in osteoblastic cells alters transcriptional activity of osteoblastspecific promoters (Lecanda et al., 1998). 
GJC is affected by various treatments. Prostaglandin E2 or PTH increases the expression of Cx43 mRNA and the formation of gap junctions (Civitelli et al., 1998; Massas and Benayahu, 1998). The timing of PTH treatment, that increases matrix mineralization, coincides with the highest expression of Cx43 (Schiller et al., 2001b). However, estrogen uncouples osteoblastic cells (Massas et al., 1998). Exposure of osteoblastic cells to magnetic fields leads to an inhibition of the cell growth which is independent of GJC, but ALP activity is dependent on GJC (Vander Molen et al., 2000). Serial passage of MC3T3-E1 cells reduces changes in cell morphology, GJC and responsiveness to TGF-B1 and BMP-2 (Chung et al., 1999). Genetic deficiency in $C x 43$ causes a delayed ossification, cranofacial abnormalities and osteblast dysfunction (Lecanda et al., 2000). Cells rendered Cx43 deficient through antisense transfection retained the osteblastic characteristics but displayed a dramatic attenuation in the cAMP response to PTH (Vander Molen et al., 1996). Furthermore, an inhibition of GJC induces transdifferentiation of osteoblasts to an adipocytic phenotype in vitro (Schiller et al., 2001c)

The morphological findings were confirmed by biochemical analysis. Differences between monolayer and micromass cultures were also observed at the biochemical level. The micromass cultures had a higher ALP activity relative to the DNA or protein content than the monolayer cultures at 1 week, but at 2 or 3 weeks these values were similar. The cells inoculated as a monolayer had to proliferate to establish cell-cell contacts. These changes were reflected by a significant increase in the DNA content and ALP activity in monolayer cultures during the second and the third weeks of culture, whereas the DNA accumulation and ALP activity in micromass cultures was non significant over the culture period.

The morphological and biochemical results were consistent with those reported in he literature (Aronow et al., 1990; Aubin 1999; Bellows et al., 1991; Bhargava et al., 1988; Ecarot-Charrier et al., 1983; Gerstenfeld et al., 1993; Masquelier et al., 1990; Nefussi et al., 1997; Owen et al., 1990; Wiestner et al., 1981; Zimmermann et al., 1988; Zimmermann et al., 1991). This indicated that the cells studied were normal, as determined by these criteria.

In conclusion, micromass culture probably promoted the differentiation of osteoblasts by promoting early cellcell contacts, by increasing the formation of collagen and by decreasing the proliferation. The micromass culture system seemed to mimic the in vivo condensation processes, which is a pivotal stage in skeletal development (Hall and Miyake, 2000). During intramembranous bone formation preosteoblast alkaline phosphatase positive cells form before condensation but after the epithelial-mesenchymal interaction upon which preosteoblast formation and condensation depend. Preosteoblasts then condense, transform into osteoblasts and deposit bone matrix. Condensation amplifies the number of preosteoblasts (Dunlop and Hall, 1995). The cells in the condensation have a dramatically increased cell-cell communication, increased cell-cell contact, attain a rounded morphology and increase the number of gap junctions (Civitelli et al., 2002; Coelho and Kosher, 1991; Marie, 2002; Thorogood and Hinchliffe, 1975). The micromass culture system therefore provides a convenient culture model of the in vivo process, upon which further experiments may be possible.

\section{Acknowledgements}

We thank Joy Buchanan for correcting the manuscript and Dr. Dominik Pfluger for the statistical analysis.

\section{References}

Arana-Chavez VE, Soares AM, Katchburian E (1995) Junctions between early developing osteoblasts of rat calvaria as revealed by freeze-fracture and ultrathin section electron microscopy. Arch Histol Cytol 58:285-292.

Aronow MA, Gerstenfeld LC, Owen TA, Tassinari MS, Stein GS, Lian JB (1990) Factors that promote progressive development of the osteoblast phenotype in cultured fetal rat calvaria cells. J Cell Physiol 143:213-221.

Aubin JE (1999) Osteoprogenitor cell frequency in rat bone marrow stromal populations: role for heterotypic cellcell interactions in osteoblast differentiation. J Cell Biochem 72:396-410.

Bellows CG, Aubin JE, Heersche JN (1991) Initiation and progression of mineralization of bone nodules formed in vitro: the role of alkaline phosphatase and organic phosphate. Bone Miner 14:27-40.

Bhargava U, Bar-Lev M, Bellows CG, Aubin JE (1988) Ultrastructural analysis of bone nodules formed in vitro by isolated fetal rat calvaria cells. Bone 9:155-163.

Bruckner P, Horler I, Mendler M, Houze Y, Winterhalter KH, Eich-Bender SG, Spycher MA (1989) Induction and prevention of chondrocyte hypertrophy in culture. J Cell Biol 109:2537-2545.

Chung CY, Iida-Klein A, Wyatt LE, Rudkin GH, Ishida K, Yamaguchi DT, Miller TA (1999) Serial passage of MC3T3-E1 cells alters osteoblastic function and responsiveness to transforming growth factor-betal and bone morphogenetic protein-2. Biochem Biophys Res Commun 265:246-251.

Civitelli R, Ziambaras K, Warlow PM, Lecanda F, Nelson T, Harley J, Atal N, Beyer EC, Steinberg TH (1998) Regulation of connexin 43 expression and function by prostaglandin E2 (PGE2) and parathyroid hormone (PTH) in osteoblastic cells. J Cell Biochem 68:8-21.

Civitelli R, Lecanda, F.,Jorgensen,N.R.,Steinberg,T.H. (2002) Intercellular junctions and cell-cell communication in bone. In: Bilezikian JP, Raisz,L.G.,Rodan,G.A. (ed) Principles in bone biology, vol. 1, 2 edn. Academic Press, San Diego, pp 287-302.

Coelho CN, Kosher RA (1991) Gap junctional communication during limb cartilage differentiation. Dev Biol 144:47-53.

Collin P, Nefussi JR, Wetterwald A, Nicolas V, BoyLefevre ML, Fleisch H, Forest N (1992) Expression of collagen, osteocalcin, and bone alkaline phosphatase in a mineralizing rat osteoblastic cell culture. Calcif Tissue 
Int 50:175-183.

Donahue HJ, Li Z, Zhou Z, Yellowley CE (2000) Differentiation of human fetal osteoblastic cells and gap junctional intercellular communication. Am J Physiol Cell Physiol 278:C315-322.

Dunlop LL, Hall BK (1995) Relationships between cellular condensation, preosteoblast formation and epithelial-mesenchymal interactions in initiation of osteogenesis. Int J Dev Biol 39:357-371.

Ecarot-Charrier B, Glorieux FH, van der Rest M, Pereira G (1983) Osteoblasts isolated from mouse calvaria initiate matrix mineralization in culture. J Cell Biol 96:639-643.

Gerstenfeld LC, Chipman SD, Glowacki J, Lian JB (1987) Expression of differentiated function by mineralizing cultures of chicken osteoblasts. Dev Biol 122:4960 .

Gerstenfeld LC, Riva A, Hodgens K, Eyre DR, Landis WJ (1993) Post-translational control of collagen fibrillogenesis in mineralizing cultures of chick osteoblasts. J Bone Miner Res 8:1031-1043.

Gramsch B, Gabriel HD, Wiemann M, Grummer R, Winterhager E, Bingmann D, Schirrmacher K (2001) Enhancement of connexin 43 expression increases proliferation and differentiation of an osteoblast-like cell line. Exp Cell Res 264:397-407.

Hall BK, Miyake T (2000) All for one and one for all: condensations and the initiation of skeletal development. Bioessays 22:138-147.

Hancox NM, Boothroyd B (1965) Electron microscopy of the early stages of osteogenesis. Clin Orthop 40:153161

Labarca C, Paigen K (1980) A simple, rapid, and sensitive DNA assay procedure. Anal Biochem 102:344-352. Laemmli UK (1970) Cleavage of structural proteins during the assembly of the head of bacteriophage T4. Nature 227:680-685.

Lecanda F, Towler DA, Ziambaras K, Cheng SL, Koval M, Steinberg TH, Civitelli R (1998) Gap junctional communication modulates gene expression in osteoblastic cells. Mol Biol Cell 9:2249-2258.

Lecanda F, Warlow PM, Sheikh S, Furlan F, Steinberg TH, Civitelli R (2000) Connexin43 deficiency causes delayed ossification, craniofacial abnormalities, and osteoblast dysfunction. J Cell Biol 151:931-944.

Marie PJ (2002) Role of N-cadherin in bone formation. J Cell Physiol 190:297-305.

Masquelier D, Herbert B, Hauser N, Mermillod P, Schonne E, Remacle C (1990) Morphologic characterization of osteoblast-like cell cultures isolated from newborn rat calvaria. Calcif Tissue Int 47:92-104.

Massas R, Benayahu D (1998) Parathyroid hormone effect on cell-to-cell communication in stromal and osteoblastic cells. J Cell Biochem 69:81-86.

Massas R, Korenstein R, Benayahu D (1998) Estrogen modulation of osteoblastic cell-to-cell communication. J Cell Biochem 69:282-290.

Nefussi JR, Brami G, Modrowski D, Oboeuf M, Forest N (1997) Sequential expression of bone matrix proteins during rat calvaria osteoblast differentiation and bone nodule formation in vitro. J Histochem Cytochem 45:493503.

Owen TA, Aronow M, Shalhoub V, Barone LM, Wilming L, Tassinari MS, Kennedy MB, Pockwinse S, Lian JB, Stein GS (1990) Progressive development of the rat osteoblast phenotype in vitro: reciprocal relationships in expression of genes associated with osteoblast proliferation and differentiation during formation of the bone extracellular matrix. J Cell Physiol 143:420-430.

Palazzini S, Palumbo C, Ferretti M, Marotti G (1998) Stromal cell structure and relationships in perimedullary spaces of chick embryo shaft bones. Anat Embryol (Berl) 197:349-357.

Reynolds ES (1963) The use of lead citrate at high $\mathrm{pH}$ as an electron opaque stain in electron microscopy. J Cell Biol 17:208-212.

Romanello M, Moro L, Pirulli D, Crovella S, D'Andrea P (2001) Effects of cAMP on intercellular coupling and osteoblast differentiation. Biochem Biophys Res Commun 282:1138-1144.

Schiller PC, D'Ippolito G, Balkan W, Roos BA, Howard GA (2001a) Gap-junctional communication is required for the maturation process of osteoblastic cells in culture. Bone 28:362-369.

Schiller PC, D'Ippolito G, Balkan W, Roos BA, Howard GA (2001b) Gap-junctional communication mediates parathyroid hormone stimulation of mineralization in osteoblastic cultures. Bone 28:38-44.

Schiller PC, D'Ippolito G, Brambilla R, Roos BA, Howard GA (2001c) Inhibition of gap-junctional communication induces the trans-differentiation of osteoblasts to an adipocytic phenotype in vitro. J Biol Chem 276:14133-14138.

Shapiro F (1997) Variable conformation of GAP junctions linking bone cells: a transmission electron microscopic study of linear, stacked linear, curvilinear, oval, and annular junctions. Calcif Tissue Int 61:285-293.

Thorogood PV, Hinchliffe JR (1975) An analysis of the condensation process during chondrogenesis in the embryonic chick hind limb. J Embryol Exp Morphol 33:581-606.

Trelstad RL, Hayashi K (1979) Tendon collagen fibrillogenesis: intracellular subassemblies and cell surface changes associated with fibril growth. Dev Biol 71:228-242.

Vander Molen MA, Rubin CT, McLeod KJ, McCauley LK, Donahue HJ (1996) Gap junctional intercellular communication contributes to hormonal responsiveness in osteoblastic networks. J Biol Chem 271:12165-12171.

Vander Molen MA, Donahue HJ, Rubin CT, McLeod KJ (2000) Osteoblastic networks with deficient coupling: differential effects of magnetic and electric field exposure. Bone 27:227-231.

Weinger JM, Holtrop ME (1974) An ultrastructural study of bone cells: the occurrence of microtubules, microfilaments and tight junctions. Calcif Tissue Res 14:15-29.

Wiestner M, Fischer S, Dessau W, Muller PK (1981) Collagen types synthesized by isolated calvarium cells. Exp Cell Res 133:115-125. 
Zimmermann B, Wachtel HC, Somogyi H, Merker HJ, Bernimoulin JP (1988) Bone formation by rat calvarial cells grown at high density in organoid culture. Cell Differ Dev 25:145-154.

Zimmermann B, Wachtel HC, Noppe C (1991) Patterns of mineralization in vitro. Cell Tissue Res 263:483493.

\section{Discussion with Reviewer}

D. Wheatley. The authors claim the importance of the promoting effect of GLCs but this cannot be done from EM or biochemical analysis. All that one can do is note a greater preponderance of GLCs in one case as opposed to another. Anything more is mere speculation..

Authors: The aim of the experiments was not to analyse the effects of gap junctional communications (GJC) per $s e$, but to compare monolayer and micromass cultures to investigate the effects of a close neighborhood of the cells shortly after inoculation. We have clear evidence that the micromass culture technique is promoting the differen- tiation of rat calvarial osteoblast-like cells by allowing cell-cell contact, directly after inoculation of the cells. We found, by TEM, that many different cell-cell contacts, as well as abundant collagen fibrils in the ECM, are present at 1 week. Furthermore, biochemical data clearly showed that the differentiation by means of ALP activity normalized to the DNA content of the cells is increased as compared to that found in the monolayer cultures.

We did not show that GJCs are directly responsible for these observations. As pointed out in the discussion, there is much evidence that GJCs are indeed very important for normal differentiation of bone and cartilage. In addition, cell-cell adhesion molecules (CAM) e.g. N-CAM and cadherins is also crucial for normal osteoblast differentiation and osteogenesis (for review see Civitelli et al., 2002; Hall and Miyake, 2000; Marie, 2002; all references cited in text). Micromass culture technique offers a convenient tool to investigate such important mediators of cellular communication like GJC, CAM and cell surface receptors by blocking them directly by antibodies or by genetic modifications of such molecules etc. 